\title{
Novel autoantibodies in rheumatoid arthritis
}

\author{
A.F. Bonifacio, A. Alunno, G.M.C. La Paglia, E. Valentini, \\ M.C. Leone, E. Bartoloni, R. Gerli \\ Rheumatology Unit, Department of Medicine, University of Perugia, Italy
}

\begin{abstract}
SUMMARY
Rheumatoid factor and antibodies against cyclic citrullinated peptides represent a diagnostic hallmark in rheumatoid arthritis (RA). However, over the last decades many other autoantibodies have been identified. Several proteins can trigger an aberrant autoimmune response in their native form while others acquire this feature after post-translational modifications such as citrullination, carbamylation or acetylation. It is of interest that also the enzymes catalyzing such post-translational modifications (e.g. the protein arginine deiminases) can transform themselves into autoantibodies in RA. The purpose of this review article is to provide an overview of relevant literature published over the last years regarding novel autoantibodies and their possible diagnostic and prognostic significance in RA.
\end{abstract}

Key words: Rheumatoid arthritis; Autoantibodies; Citrullination.

Reumatismo, 2019; 71 (1): 1-12

\section{INTRODUCTION}

$\mathrm{R}$ heumatoid arthritis (RA) is the most common and heterogeneous chronic inflammatory joint disease primarily affecting synovial joints. It is characterized by erosive arthritis, extra-articular manifestations, disability and mortality, the latter mainly due to cardiovascular events and respiratory complications (1).

Although the exact cause of the disease is still unknown, the identification of a number of etiopathogenic features, such as the presence of auto-antibodies (Abs) directed against citrullinated proteins (ACPA) and the increased production of inflammatory cytokines, including tumor necrosis factor (TNF)- $\alpha$, interleukin (IL)-1 $\beta$, IL-6 and IL17 (2), has led in recent years to substantial innovations in both diagnosis and treatment of the disease and consequent improvement of the prognosis. It is now evident, in fact, that early diagnosis and aggressive treatment with conventional synthetic (cs) and biologic (b) disease modifying anti-rheumatic drugs (DMARDs) in patients with RA may prevent irreversible bone loss and life-time disability (3). Although Abs against many different epitopes are continuously identi- fied in the serum of RA patients, actually only 2 types of autoAbs, rheumatoid factor (RF) and Abs directed against synthetic cyclic citrullinated peptides (anti-CCP), are recognized as having a diagnostic and prognostic value and have been included in the 2010 American College of Rheumatology (ACR) RA classification criteria $(4,5)$.

$\mathrm{RF}$, an $\mathrm{Ab}$ recognizing the $\mathrm{Fc}$ or conserved portion of human Abs, was the first biological criterion included in the ACR criteria of 1987 (4), showing a great sensitivity for established RA and allowing identification of patients with persistent and/or erosive disease. It was, therefore, the first recognized prognostic marker in RA. However, RF presents two main disadvantages: low diagnostic specificity, since it could be also detected in other autoimmune diseases, infectious disorders, malignancies, other connective tissue diseases and in a proportion of healthy controls, and low prevalence in the initial phases of the disease (6). ACPA are the second biological criterion introduced in the 2010 ACR/EULAR RA classification (5), as they display a higher specificity, could be detectable also in the pre-clinical and early stages of the disease and correlate with erosive disease (6). $\overline{\text { Corresponding author: }}$

Roberto Gerli

Rheumatology Unit, Department of Medicine

University of Perugia

Piazzale Menghini - 06129 Perugia, Italy E-mail: roberto.gerli@unipg.it 
In this review, we provide an overview of the past 5 years of scientific literature about novel autoAbs and their possible diagnostic, clinical, prognostic and predictive significance in RA.

\section{CITRULLINATED PEPTIDES}

Citrullination is a post-translational modification catalyzed by the enzyme peptidylarginine deiminase (PAD), leading to the conversion of arginine residues into the non-standard amino-acid citrulline. This process determines the loss of a positive charge with a very small change in molecular mass and can influence the ability to form hydrogen bond and therefore the interaction with other amino-acids residue. Citrullination leads to the creation of a new protein with conformational and possibly functional alteration but, most importantly, it leads to the formation of new immunogenic epitopes, eventually triggering an aberrant immune response in genetically predisposed individuals (7).

Anti-perinuclear factor (APF) (8) and anti-keratin antibodies (AKA) (9) were described for the first time in RA patients in 1964 and 1979 respectively, but only in 1998 did Schellekens et al. (10) identify citrullinated pro-filaggrin as the target of these 2 autoAbs. This was the first evidence of the importance of citrullination in the pathogenesis and immunologic response of RA.

ACPA entered the clinical routine after the development of ELISA tests based on the recognition of anti-CCP (11) showing great specificity and good sensitivity. Nowadays second generation anti-CCP2 assays are used in clinical practice, raising the specificity around $96 \%$ with a sensitivity that ranges from $67 \%$ to $78 \%$ in patients with established RA and $57 \%$ in patients with early RA (12). ACPA can be detected in early RA and in RF-negative patients and are associated with more severe joint destruction (13).

$\mathrm{CCP}$ are not the real epitopes recognized by ACPA, as many citrullinated proteins seem to be the actual target of these Abs and numerous assays detecting these epitopes have been developed in the past years (Table I).

\section{Vimentin: anti-mutated citrullinated vimentin/anti-Sa}

One of the most important citrullinated antigen targets of ACPA is vimentin, an intermediary filament fundamental for cell

Table I - ACPA fine specificities epitopes and related antibodies.

\begin{tabular}{|c|c|c|c|c|}
\hline Epitopes & Antibodies & Sensitivity & Specificity & Reference \\
\hline Pro-filaggrin / Keratin & $\begin{array}{c}\text { AKA } \\
\text { APF } \\
\text { Anti-fil 306-326 } \\
\text { Anti-fil 311-315 } \\
\text { Anti-keratin 8 }\end{array}$ & $\begin{array}{c}48 \% \\
- \\
42 \% \\
72 \% \\
68 \%\end{array}$ & $\begin{array}{c}98 \% \\
- \\
95 \% \\
95 \% \\
80 \%\end{array}$ & $\begin{array}{c}(16) \\
- \\
(17) \\
(17) \\
(29)\end{array}$ \\
\hline Vimentin & $\begin{array}{l}\text { Anti-MCV } \\
\text { Anti-Sa }\end{array}$ & $\begin{array}{l}39-79 \% \\
37-50 \%\end{array}$ & $\begin{array}{c}73.8-100 \% \\
97-99 \%\end{array}$ & $\begin{array}{l}(16-18) \\
(19,20)\end{array}$ \\
\hline Alpha-enolase & Anti-CEP1 & $44 \%$ & $97 \%$ & (39) \\
\hline Fibrinogen/Fibrin & 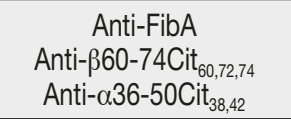 & $\begin{array}{c}48 \% \\
70-73 \% \\
45-50 \%\end{array}$ & $\begin{array}{l}95 \% \\
95 \% \\
95 \% \\
\end{array}$ & $\begin{array}{c}(32) \\
(32,33) \\
(32,33)\end{array}$ \\
\hline Viral peptides & $\begin{array}{c}\text { Anti-EBNA35-58Cit } \\
\text { Anti-VCP2 }\end{array}$ & $\begin{array}{l}36 \% \\
61 \%\end{array}$ & $\begin{array}{l}98 \% \\
95 \%\end{array}$ & $\begin{array}{l}(35) \\
(23)\end{array}$ \\
\hline $\begin{array}{l}\text { Glucose-6.phosphate } \\
\text { isomerase }\end{array}$ & $\begin{array}{c}\text { Anti-GPI } \\
\text { Anti CCG (1-9) }\end{array}$ & $\begin{array}{c}75 \% \\
-\end{array}$ & $\begin{array}{c}64 \% \\
-\end{array}$ & $\begin{array}{l}(16) \\
(39)\end{array}$ \\
\hline Collagen & $\begin{array}{l}\text { Anti-telopeptides type I } \\
\text { Anti-telopeptides typell } \\
\text { Anti-type II collagen }\end{array}$ & $\begin{array}{l}47 \% \\
41 \% \\
30 \%\end{array}$ & $\begin{array}{c}96 \% \\
94 \% \\
-\end{array}$ & $\begin{array}{l}(24) \\
(24) \\
(17)\end{array}$ \\
\hline
\end{tabular}


Table II - Sensitivity and specificity of antibodies directed against vimentin-derived peptides.

\begin{tabular}{|l|c|c|c|c|c|}
\hline Author & Year & $\mathbf{N}^{\circ}$ patients & Sensitivity & Specificity & Reference \\
\hline Anti-MCV & 2015 & 170 & $61 \%$ & $100 \%$ & $(18)$ \\
\hline Reyes-Castillo et al. & 2014 & 225 & $70 \%$ & N/A & $(26)$ \\
\hline Gonzalez-Lopez et al. & 2013 & 41 & $79 \%$ & $74 \%$ & $(16)$ \\
\hline Zhu et al. & 2013 & 592 & $39 \%$ & $96 \%$ & $(21)$ \\
\hline Nicaise-Roland et al. & 2012 & 285 & $59 \%$ & $95 \%$ & $(23)$ \\
\hline Bartoloni et al. & 2013 & 263 & $44 \%$ & $95 \%$ & $(17)$ \\
\hline Szarka et al. & 2012 & 198 & $50 \%$ & $99 \%$ & $(20)$ \\
\hline Anti-Sa & 2015 & 41 & $37 \%$ & $97 \%$ & $(19)$ \\
\hline Hou et al.
\end{tabular}

structure, and Abs directed against vimentin may be among of the first to develop in the preclinical phase of the disease. To date, two ELISA assays to detect anti-vimentin Abs exist, the first directed against citrullinated vimentin (named after a patient as anti-Savoie/anti-Sa), the second directed against mutated citrullinated vimentin (MCV), a peptide with insertion of a glycine residue instead of an arginine residue $(14,15)$.

The sensitivity of anti-MCV Abs in RA patients ranges from $39 \%$ to $78.6 \%$ and the specificity between $74 \%$ to $100 \%$ (16-18), while anti-Sa Abs display lower sensitivity $(37 \%-50 \%)$ but higher specificity (9799\%) $(19,20)$ (Table II).

The presence of Abs directed against MCV strongly correlates with the presence of anti-CCP Abs (19-21). An interesting concordance has been also found between anti-Sa $\mathrm{Ab}$ status and presence/titer of $\mathrm{Abs}$ directed against carbamylated proteins (22). Some studies, comparing the diagnostic value of anti-MCV and anti-CCP Abs, did not find further diagnostic information from the addition of anti-MCV to anti-CCP detection $(18,23)$. Only Zhu et al. (16) found that the combined detection of anti-MCV and anti-CCP Abs increased the sensibility to $89 \%$ compared with anti-CCP alone $(68 \%)$ and anti-MCV alone (79\%), but with a loss of specificity of antiCCP from $98 \%$ to $74 \%$ in a small cohort of RA and mixed connective tissue disease (MCTD) patients.
An interesting data point is also that the presence of anti-MCV autoAbs in patients with undifferentiated arthritis (UA) is correlated with the development of RA with a positive predictive value (PPV) of $72.5 \%$ (21).

Anti-MCV and anti-Sa Abs also seem to be associated with disease activity, since a statistically significant direct correlation was found with disease activity score on 28 joints (DAS28) $(18,20)$, and with development of erosive disease (24).

A positive correlation was found also between anti-MCV Abs, erythrocyte sedimentation rate (ESR), C-reactive protein (CRP) and disease duration (18), whereas this association was not confirmed for anti-Sa Abs (19, 20). Conflicting results concerning the association between these autoAbs and radiological articular damage have been recently reported $(19,20,24)$.

Reyes-Castillo et al. (18) found a strong correlation between the presence of antiMCV Abs and Th1 (TNF- $\alpha$, IL-1 $\beta$ ) and Th2 (IL-4, IL-6, IL-10, IL-2) related cytokines levels, but not with IL-17, in a cohort of 170 RA patients. Furthermore, a relationship between the homozygous susceptibility haplotype of PADI4 gene and levels of anti-MCV Abs has been also described.

A strong association between anti-MCV levels and extra-articular manifestation of RA, in particular Felty's syndrome and major cutaneous vasculitis, has been found in a small cohort of RA patients (25). Another study, examining the possible association 
between anti-MCV and extra-articular RA manifestations, detected only a weak association with rheumatoid nodules (26).

Anti-MCV seem to be also a predictive marker of response to rituximab (RTX) treatment as patients responding to this biological agent were characterized by a restrictive $\mathrm{Ab}$ response of anti-MCV IgG, while double positivity for anti-MCV IgG and IgA was associated with response failure to RTX (27).

Filaggrin and keratin: the anti-keratin Abs Keratin and filaggrin, two intermediate filaments, were the first two epitopes recognized as targets of autoAbs in RA patients, the so called AKA, that were first described in 1979 in RA serum (9). One of the targets of these Abs was later identified as citrullinated pro-filaggrin (28).

Recently, AKA showed the highest specificity (98\%), but the lowest sensitivity $(48 \%)$, in a diagnostic comparison with anti-MCV Abs and anti-glucose-6-phosphate isomerase (GPI) Abs (16).

Abs against keratin $8(\mathrm{~K} 8)$ were identified in a small group of 50 patients with RA with a sensitivity of $68 \%$ and a specificity of $80 \%$ and $\mathrm{K} 8$ was probably one of the real targets of the traditional AKA (29). Data obtained with a Multipin ELISA analysis showed that two citrullinated filaggrin fragments, the fil306-326 and its minimal epitope fil311315 , were recognized by RA sera with a sensitivity of $42 \%$ and $72 \%$, respectively, but a high specificity (95\%) (17).

\section{Fibrin and fibrinogen: anti-hFibA Abs}

Citrullinated fibrin was identified as one of the main ACPA autoantigens in the synovial tissue of RA patients (30) and an ELISA test was developed to detect Abs to human citrullinated fibrinogen (hFibA) (31).

Anti-hFibA Abs showed a sensitivity of $48 \%$ and a specificity of $95 \%$ in RA patients and a sensitivity of $32 \%$ with a specificity of $88 \%$ in predicting the progression to RA in a cohort of patients affected by UA. Disability, as quantified by the health assessment questionnaire (HAQ), and disease activity (DAS28) were directly correlated with the presence of anti-hFibA Abs (21).

In a cohort of established RA patients,
Abs directed against 2 fibrin epitopes $\beta 60$ ${ }_{74 \mathrm{Cit}_{60,72,74}}$ and $\alpha 36-50 \mathrm{Cit}_{38,42}$, showed a sensitivity of $70 \%$ and $50 \%$ respectively (diagnostic thresholds specificity of 95\%). An interesting piece of data was that $90 \%$ of the RA sera with circulating anti-hFibA Abs contained one or both the subfamilies of autoAbs (32).

In a cohort of black-African RA patients, anti-hFibA Abs displayed a sensitivity of $73 \%$, and, similarly to Cornillet's study (32), Abs against $\alpha 36-50 \mathrm{Cit}_{38,42}$ and $\beta 60$ 74Cit $60,72,74$ were detected respectively in $45 \%$ and $73 \%$. Anti- $\beta 60-74 \mathrm{Cit}_{60,72,74} \mathrm{Abs}$ had also a statistically significant association with HLA-DRB1 SE (33).

\section{Viral citrullinated peptide}

Involvement of the Epstein Barr Virus (EBV) in RA pathogenesis was suggested when Abs recognizing a nuclear antigen of EBV-transformed lymphocytes were found in RA sera. The antigen target of these Abs was initially called RA nuclear antigen (RANA) and later identified as the EBNA1 viral protein (34).

EBNA35-58Cit is a synthetic citrullinated multiple antigen peptide bearing four identical sequences derived from the EBNA-1 region of the genome of EBV. Abs directed against this epitope were found in $36 \%$ of established RA patients with a specificity of $98 \%$, and were directly correlated with the presence of anti-hFibA, thereby suggesting a cross-reactivity between these two autoAbs (35).

Viral citrullinated peptide 2 (VCP2), a peptide corresponding to the sequence 338358 of the EBV encoded protein (EBNA2 ), is another target of specific Abs in RA sera. The diagnostic performance of antiVCP2 Abs was compared with anti-MCV in a large cohort of RA patients, revealing a similar sensitivity $(61 \%$ and $59 \%$ respectively), but higher specificity for anti-VCP2 (95\% vs $92 \%$ ) (23).

\section{Collagen and telopeptides}

Collagen is the main component of connective tissue. Abs directed against collagen type II are present in about 30\% of RA patients and correlate with HLA-DR4 
(36). Abs against citrullinated collagen II peptide showed a sensibility of $41 \%$ and a specificity of $95 \%$ (17).

In addition, Abs recognizing citrullinecontaining sequences related to type I and II collagen telopeptides can be found in sera of RA patients with a sensitivity of $47 \%$ and $41 \%$ and a specificity of 96 and $94 \%$ respectively (24).

Finally, Abs reactive against citrullinatedcarboxy-terminal telopeptides of type I and type II collagen have been observed in both seronegative and seropositive RA patients, even in samples collected before the development of the disease, and their titer was higher compared to controls (37).

\section{Alpha-enolase 1: anti-CEP1}

Alpha-enolase 1 is a glycolytic isoenzyme that catalyzes the conversion of 2-phosphoglycerate to phosphoenolpyruvate. Abs directed against citrullinated alpha-enolase 1 (CEP1) were shown to be a portion of ACPA fine specificity in RA patients (38). Anti-CEP1 Abs were detected in $44.2 \%$ of RA patients with a specificity of $97.3 \%$ and were associated with HLA-DRB1 SE alleles in a Japanese cohort (39). Furthermore, an association between anti-CEP1 and PTPN22 has been also reported $(40,41)$.

In another cohort of $248 \mathrm{RA}$ patients, anti-CEP1 and anti-P. Gingivalis Ab levels were higher in RA patients than in controls and correlated each other. Moreover, anti-CEP1 also correlated with periodontal disease and RA disease activity (42). Conflicting data, however, have been reported with regard to the association of CEP1 and erosive RA $(41,43)$

Glucose-6-phosphate isomerase: anti-GPI Glucose-6-phosphate isomerase (GPI) is another major glycolytic enzyme and was first described as an arthritogenic target in a mouse model, in which arthritis was sustained almost completely by autoAbs to GPI (44).

Anti-citrullinated-GPI Abs have been recently identified for the first time in the sera of RA patients. In particular, Abs against 9 cyclic citrullinated peptides spanning the whole GPI sequence (CCG 1-9) have been described by Umeda et al (39). AntiCCG-2 and anti-CCG-7 Abs were highly specific for RA, their titers correlated with the presence of HLA-DRB1 SE alleles and with RA disease activity. Furthermore, the treatment with TNF antagonists was able to reduce their titers.

In a study comparing ACPA fine specificities, Zhu et al. found that anti-GPI had the lowest specificity (64\%) and a sensitivity of $75 \%$ compared with anti-CCP, antiMCV, anti-AKA (16).

\section{Novel citrullinated targets}

Van Beers et al. (45) identified new citrullinated epitopes as targets of the immune system in RA, including citrullinated apolipoprotein E (ApoE), myeloid cell nuclear differentiation antigen (MNDA) and $\beta$-actin. These Abs were detected in the sera of patients with established RA with a sensitivity of $27 \%, 16 \%, 27 \%$ and a specificity of $96 \%, 97 \%, 98 \%$, respectively.

The great interest towards Abs targeting citrullinated peptides led to a consistent bulk of data that, however, needs to be validated in larger studies. Some Abs including antiMCV seem to be a predictive marker of progression to RA in UA patients (21-37), and some anti-MCV isotypes seems to be associated with extra-articular manifestations (25) or the response to rituximab (27).

Overall, in our opinion these data show no real clinical benefit for the assessment of a single epitope $\mathrm{Ab}$ instead of anti-CCP, as their sensitivity and specificity seems to be quite similar or even lower compared to anti-CCP (Table I). Likewise, the correlation with disease severity of these novel Abs appears to overlap that of anti-CCP.

Conflicting results have been reported regarding the relevance of the detection of multiple specificities Abs in RA diagnosis in comparison to anti-CCP alone (16-21). However, additional data are needed to draw definitive conclusions in this regard.

\section{PEPTIDIL-ARGININE DEIMINASE (PADS)}

Besides citrullinated proteins, it is interesting to note that also PADs, the enzymes 
catalyzing citrullination, may represent a target antigen for autoAbs in RA. PADs are calcium-dependent enzymes and five isoforms have been described in humans (1-4 and 6). In particular, PAD3 and PAD4 emerged as key participants in the pathogenesis of RA (46) and targets of autoAbs in RA sera (47). Among all the isoforms, PAD4 seems to be the most relevant target. Anti-PAD4 sensitivity ranges from $24 \%$ to $37 \%(18,48-51)$, while specificity, determined only in two studies, appears to reach $95-100 \%(18,51)$. Anti-PAD4 Abs have been directly correlated with disease duration (18) and with the presence of antiCCP Abs (18, 48-51). Conversely, no association was found between anti-PAD4 Abs and Th2-Th1 cytokines levels (18) or HLA DRB1-SE (51). It is worth noting that patients with anti-PAD4 Abs also had negligible levels of serum human PAD4 (48).

PAD3 is another recognized target of serum autoAbs in RA patients and anti-PAD3 sensitivity varied between $11 \%$ and $18 \%$. Similarly to anti-PAD4, the presence of anti-PAD3 Abs was associated with the presence of anti-CCP Abs $(50,52)$.

It has been shown that patients with antiPAD3 Abs had a higher baseline Sharp van der Heijde $(\mathrm{SvdH})$ score than those with anti-PAD4 alone. In addition, anti-PAD3 Abs were also associated with longer disease duration, radiographic progression and erosive disease $(50,52)$. Finally, the presence of anti-PAD3/4 cross-reactive antibodies seemed to be associated also with the presence and the extent of interstitial lung disease (ILD) assessed by computed tomography (CT) scan (50).

\section{CARBAMYLATED PROTEINS}

Carbamylation is a post-translational process in which cyanate binds to primary amino or thiol groups. This process is enhanced by inflammation via a mechanism, which depends on myeloperoxidase (MPO) and lysine carbamoyltransferase, the enzymes that catalyze the carbamylation of a lysine residue into homocitrulline (53). Carbamylation is involved in many pathological processes including chronic kidney disease, cardiovascular disease and cataract, but it is interesting to underline that Abs to carbamylated proteins (Carbp), in particular carbamylated-fetal-calf-serum (Ca-FCS) and carbamylated-fibrinogen (Ca-Fib), have been identified in the sera of RA patients (54).

These Abs have been observed in the sera of patients years before disease onset (55, 56) and their presence in patients with UA (57) or arthralgia $(58,59)$ was significantly associated with future development of RA independently of other ACPA and RF status. The reported sensitivity of anti-Carbp Abs in RA is $18-26 \%$ in patients prior to the diagnosis, and $27-46 \%$ in patients with overt RA, while the specificity varies between $89 \%$ and $97 \%$. (22, 55-63) (Table III).

There is evidence that positivity for antiCarbp Abs is also associated with the presence of anti-CCP and anti-Sa and correlates with the titers of these Abs (22). Likewise, only a small percentage, $6.1-29.5 \%$, of seronegative (CCP, RF) RA patients were positive for anti-Carbp Abs $(22,55,58,59)$, and $11 \%$ of the sera of seronegative patients collected before the diagnosis were tested positive for anti-Carbp Abs (56).

Anti-Carbp Abs were also directly correlated with disease activity (DAS28), disability (HAQ) and the presence of joint erosions $(60,62)$.

Interestingly, the presence of anti-Carbp Abs before the onset of disease symptoms predicted the radiological findings at baseline and correlated with the rate of radiological destructions (55).

In contrast to these results, no correlation between anti-Carbp Abs and DAS28, radiological damage, ESR or PCR levels was found by Challener et al. (22).

With regard to genetic factors, in a retrospective study on two cohorts of patients, Jiang et al. (61) found no correlations between the presence of anti-CarbP Abs and PTPN22 polymorphism or HLA-DRB1-SE alleles. The same study ruled out the association between anti-Carbp Abs and smoking. Data about anti-CarbP Abs are nowadays consistent and allow us to make some considerations. The main clinical relevance of anti-Carbp Abs is represented by their di- 
Table III - Sensitivity and specificity of anti-Carbp antibodies.

\begin{tabular}{|l|c|c|c|c|c|}
\hline Author & Year & $\mathbf{N}^{\circ}$ Pts & Sensitivity & Specificity & Reference \\
\hline Brink et al. & 2015 & 423 & $\begin{array}{c}42 \% \text { (RA patients) } \\
19 \% \text { (Prior diagnosis) }\end{array}$ & $97 \%$ & $(55)$ \\
\hline Gan et al. & 2015 & 76 & $26 \%$ (Prior diagnosis) & $95 \%$ & $(56)$ \\
\hline Yee et al. & 2014 & 120 & $30 \%$ & No controls & $(62)$ \\
\hline Shi et al. & 2014 & 79 & $\begin{array}{c}27 \% \text { (for anti-Ca-FCS) } \\
38 \% \text { (for anti-Ca-Fib) }\end{array}$ & No data & $(63)$ \\
\hline Jiang et al. & 2014 & $1985+846$ & $\begin{array}{c}36-45 \% \text { (for anti-Ca-FCS) } \\
38-43 \% \text { (for anti-Ca-Fib) }\end{array}$ & No data & (61) \\
\hline Challener et al. & 2016 & 212 & $\begin{array}{c}46 \% \text { (seropositive RA patients) } \\
9 \% \text { (seronegative RA patients) }\end{array}$ & No data & $(22)$ \\
\hline Shi et al. & 2015 & 969 & $\begin{array}{c}44 \% \\
46.8 \%\end{array}$ & $89 \%$ & $(57)$ \\
\hline Pecani et al & 2016 & 309 & $29.5 \%$ (seronegative RA patients) & $91.95 \%$ & $(59)$ \\
\hline
\end{tabular}

agnostic utility in seronegative ( $\mathrm{RF}, \mathrm{CCP}$ ) RA patients. Indeed, a proportion of RA patients ranging between $6.1 \%$ and $29.5 \%$ $(22,55,58,59)$ may benefit from the assessment in the diagnostic workout. Nevertheless, the seronegative gap is yet to be filled and further research is needed in this regard. Although these Abs display a lower sensitivity compared to anti-CCP, their correlation with the development of RA in UA and arthralgia patients appears to be of great interest.

\section{OTHER TARGETS}

The identification of novel targets of autoAbs in RA is under intense investigation. Therefore, a wide range of autoAbs, other than ACPA and anti-Carbp, are continuously identified in RA patients (Table IV). Abs against reactive oxygen species (ROS) modified type II collagen (CII) may represent a novel serologic diagnostic marker in RA. The reactivity to ROS-CII in DMARDs naive patients with early RA was significantly higher than in patients with OA and healthy control subjects. A different reactivity was also found in patients with established RA between DMARD-non-responder patients (sensitivity 58\%) and DMARDresponders (8\%) (64). No relationship has been observed between anti-ROS CII and DAS28.

Serum levels of Abs directed against N- homocysteinylated (Hcy) albumin and haemoglobin were elevated respectively in $21 \%$ and $22 \%$ RA patients compared to controls. In addition, a significant relationship between anti-N-Hcy-proteins Abs and RA duration, radiological damage and number of swollen joints was observed (65).

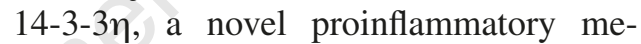
diator, involved in the pathophysiology of joint inflammation in RA, seems to be able to generate an $\mathrm{Ab}$ response as Abs against this compound have been identified in RA. The titers of these Abs were significantly higher in patients with early RA when compared with established RA patients and healthy controls, and $72 \%$ of the seronegative (CCP, RF) early RA patients were positive for anti-14-3-3 $\eta \mathrm{Abs}$. Interestingly anti-14-3-3 $\eta$ autoAbs were significantly lower at year 1 in comparison to the corresponding baseline measurement in a cohort of 62 early RA, DMARDs naïve patients, receiving therapy within a year of the first assessment (66).

Heterogeneous nuclear ribonucleoproteins (hnRNPs) are nucleoplasmic molecules interacting with pre-messenger ribonucleic acid. Abs reactive with hnRNP-B1, also called RA33, were observed in Russian patients with rheumatic diseases, in particular systemic sclerosis and RA (sensitivity $14 \%$ ) and, in the latter, they were not associated with disease activity or erosions (67). A lower sensitivity of anti-RA33 
Table IV - Novel autoantibody target of in RA.

\begin{tabular}{|l|c|c|c|}
\hline & Authors & Year & Reference \\
\hline ROS modified type II collagen & Strollo et al. & 2013 & $(64)$ \\
\hline N-homocysteinylated albumin and haemoglobin & Nawakowska-Plaza et al. & 2014 & $(65)$ \\
\hline $14-3-3 \eta$ & Maksymowych et al. & 2015 & $(66)$ \\
\hline Heterogeneous nuclear ribonucleoproteins (hnRNPs) & Maslyanskiy et al. & 2014 & $(67)$ \\
& Al-mughales et al. & 2015 & $(68)$ \\
\hline Heat shock proteins (HSP) & Shoda et al. & 2016 & $(69)$ \\
\hline$\alpha 1,4$-polygalacturonic acid (PGA) & Dai et al. & 2014 & $(70)$ \\
\hline Osteoprotegerin (OPG) & Hauser et al. & 2015 & $(71)$ \\
\hline Nuclear phosphoprotein IFN-inducible protein 16 (IFI-16) & Alunno et al. & 2016 & $(72)$ \\
\hline Tumor necrosis factor (TNF) & Lopatnikona et al. & 2013 & $(73)$ \\
\hline Malondialdehyde-Acetaldehyde & Thiele et al. & 2015 & $(74)$ \\
\hline Transthyretin (TTR) & Sharma et al. & 2014 & $(75)$ \\
\hline Tryptase & Guo et al. & 2014 & $(76)$ \\
\hline Carbonic anhydrases III (CA) & Liu et al. & 2012 & $(77)$ \\
\hline Vascular endothelial Cadherin & Bouillet et al. & 2013 & $(78)$ \\
\hline Glial fibrillary acidic protein (GFAP) & Biswas et al. & 2013 & $(79)$ \\
\hline$\alpha-1-\beta$-glycoprotein (A1BG) & Biswas et al. & 2013 & $(79)$ \\
\hline Zinc finger protein 706 (ZNF706) & Charpin et al. & 2013 & $(80)$ \\
\hline Within BGCN homolog drosophila (WIBG) & Charpin et al. & 2013 & $(80)$ \\
\hline Gaba A receptor-associated protein-like 2 (GABARAPL2) & Charpin et al. & 2013 & $(80)$ \\
\hline
\end{tabular}

(7\%) was observed in another RA cohort from Saudi Arabia (68).

Heat shock proteins (HSP) are molecular chaperones required for cell homeostasis. Abs against Mycobacterial HSPs were significantly elevated in RA patients and correlated with serum anti-binding immunoglobulin protein (BIP) Ab titers (69).

$\alpha 1,4$-polygalacturonic acid (PGA) is a major structural component of pectin. In a cohort of $100 \mathrm{RA}$ patients, when diagnostic specificity was set at 95\%, PGA-IgA and PGA-IgG Abs were detected in $65 \%$ and $77 \%$ of RA patients, respectively (70). In this study, the sensitivity of PGA-IgA Abs was $70 \%$ in early RA subjects.

AutoAbs to bone protective protein osteoprotegerin (OPG) were identified in $9 \%$ of RA patients and were associated with disease activity and increased bone resorption (71).

IFN-inducible nuclear phosphoprotein 16 (IFI-16) is a member of the HIN-200/ Ifi-200 gene family whose overexpression drives early steps of inflammatory response through NF-kb-mediated secretion of proinflammatory molecules. Circulating antiIFI16 autoAbs were identified in approximately $20 \%$ of RA patients (72).

Notably, circulating anti-TNF Abs were higher in the sera of RA patients compared to controls. In particular, IgG2, IgG3, IgG4 anti-TNF Abs were significantly higher in patients with active RA than in healthy controls, IgG2 were also significantly higher in sera of patients with active disease than in patients who had responded positively to DMARDs therapy (73).

Other epitopes were recognized as targets of autoAbs in RA like malondialdehydeAcetaldehyde (MAA) (74), transthyretin (TTR) (75), tryptase (76), carbonic anhydrases III (CAIII) (77), vascular endothelial cadherin (78), but no additional information is available at the moment.

Finally, through mass spectrometric analysis, Biswas et al. (79) identified two novel targets of autoAbs, glial fibrillary acid protein (GFAP) and $\alpha-1-\beta$-glycoprotein 
(A1BG). Moreover, Charpin et al. (80) identified zinc finger protein 706 (ZNF706), within BGCN homolog drosophila (WIBG), and gaba A receptor-associated protein-like 2 (GABARAPL2), as new targets of RA serum autoAbs.

\section{CONCLUSIONS}

The identification of novel serum biomarkers in heterogeneous and disabling diseases such as RA is helpful nowadays, not only for an early diagnosis, but also for a prognostic stratification of the patients. In fact, the early identification of subjects at higher risk of developing more aggressive forms of the disease would provide the opportunity to start a treatment before the onset of permanent damage and disability and ideally to prevent, or at least slow down, their development. Although some autoAbs already represent a reality as diagnostic and prognostic markers in RA, the identification of novel targets of immune response in RA would helpfully allow closure of the gap of seronegative RA and ensure early diagnosis, early prognostic stratification and prompt tailored treatment with a treatto-target strategy for each patient.

\section{REFERENCES}

1. Alamanos Y, Drosos AA. Epidemiology of adult rheumatoid arthritis. Autoimmun Rev. 2005; 4: 130-6.

2. McInnes I. The pathogenesis of rheumatoid arthritis. N. Engl. J. Med. 2011; 365: 2205-19.

3. Breedveld F. The value of early intervention in RA-a window of opportunity. Clin Rheumatol. 2011; 30: 33-9.

4. Arnett FC, Edworthy SM, Bloch DA, et al. The American Rheumatism Association 1987 revised criteria for the classification of rheumatoid arthritis. Arthritis Rheum. 1988; 31: 315-24.

5. Aletaha D, Neogi T, Silman AJ, et al. 2010 Rheumatoid arthritis classification criteria: An American College of Rheumatology/European League against rheumatism collaborative initiative. Arthritis Rheum. 2010; 62: 2569-81.

6. Taylor P, Gartemann J, Hsieh J, Creeden J. A systematic review of serum biomarkers anticyclic citrullinated peptide and rheumatoid factor as tests for rheumatoid arthritis. Autoimmune Dis. 2011; 815038: 1-18.
7. Valesini G, Gerardi MC, Iannuccelli C, et al. Citrullination and autoimmunity. Autoimmun Rev. 2015; 14: 490-7.

8. Nienhuis RL, Mandema E. A new serum factor in patients with rheumatoid arthritis; the antiperinuclear factor. Ann Rheum Dis. 1964; 23: 302-5.

9. Young BJJ, Mallya RK, Leslie RDG, et al. Antikeratin antibodies in rheumatoid arthritis. $\mathrm{Br}$ Med J. 1979; 2: 97-9.

10. Schellekens GA. Pillars article: citrulline is an essential constituent of antigenic determinants recognized by rheumatoid arthritis - specific autoantibodies. J Immunol. 2015; 195: 8-16.

11. Schellekens GA, Visser H, de Jong BAW, et al. The diagnostic properties of rheumatoid arthritis antibodies recognizing a cyclic citrullinated peptide. Arthritis Rheum. 2000; 43: 155-63.

12. Whiting PF, Smidt N, Sterne JAC, et al. Review annals of internal medicine systematic review: accuracy of anti-citrullinated peptide antibodies for diagnosing rheumatoid arthritis. Ann Intern Med. 2010; 152: 456-64.

13. Vallbracht I, Rieber J, Oppermann M, et al. Diagnostic and clinical value of anti-cyclic citrullinated peptide antibodies compared with rheumatoid factor isotypes in rheumatoid arthritis. Ann Rheum Dis. 2004; 63: 1079-84.

14. Bang H, Egerer K, Gauliard A, et al. Mutation and citrullination modifies vimentin to a novel autoantigen for rheumatoid arthritis. Arthritis Rheum. 2007; 56: 2503-11.

15. Vossenaar ER, Després N, Lapointe E, et al. Rheumatoid arthritis specific anti-Sa antibodies target citrullinated vimentin. Arthritis Res Ther. 2004; 6: 142-50.

16. Zhu T, Feng L. Comparison of anti-mutated citrullinated vimentin, anti-cyclic citrullinated peptides, anti-glucose-6-phosphate isomerase and anti-keratin antibodies and rheumatoid factor in the diagnosis of rheumatoid arthritis in Chinese patients. Int J Rheum Dis. 2013; 16: 157-61.

17. Szarka E, Babos F, Magyar A, et al. Recognition of new citrulline-containing peptide epitopes by autoantibodies produced in vivo and in vitro by B cells of rheumatoid arthritis patients. Ann Rheum Dis. 2013; 72: 181-91.

18. Reyes-Castillo Z, Palafox-Sánchez CA, ParraRojas I, et al. Comparative analysis of autoantibodies targeting peptidylarginine deiminase type 4, mutated citrullinated vimentin and cyclic citrullinated peptides in rheumatoid arthritis: associations with cytokine profiles, clinical and genetic features. Clin Exp Immunol. 2015; 182: 119-31.

19. Iwaszkiewicz C, Puszczewicz M, BialkowskaPuszczewicz G. Diagnostic value of the antiSa antibody compared with the anti-cyclic citrullinated peptide antibody in rheumatoid arthritis. Int J Rheum Dis. 2015; 18: 46-51. 
20. Hou YF, Sun GZ, Sun HS, et al. Diagnostic value of anti-Sa and anticitrullinated protein antibodies in rheumatoid arthritis. J Rheumatol. 2012; 39: 1506-8.

21. Nicaise-Roland P, Nogueira L, Demattei C, et al. Autoantibodies to citrullinated fibrinogen compared with anti-MCV and anti-CCP2 antibodies in diagnosing rheumatoid arthritis at an early stage: data from the French ESPOIR cohort. Ann Rheum Dis. 2013; 72: 357-62.

22. Challener GJ, Jones JD, Pelzek AJ, et al. Anticarbamylated protein antibody levels correlate with Anti-Sa (citrullinated vimentin) antibody levels in rheumatoid arthritis. J Rheumatol. 2016; 43: 273-81.

23. Bartoloni E, Alunno A, Bistoni O, et al. Diagnostic value of anti-mutated citrullinated vimentin in comparison to anti-cyclic citrullinated peptide and anti-viral citrullinated peptide 2 antibodies in rheumatoid arthritis: an Italian multicentric study and review of the literature. Autoimmun Rev. 2012; 11: 815-20.

24. Turunen S, Hannonen P, Koivula M, et al. Separate and overlapping specificities in rheumatoid arthritis antibodies binding to citrulline- and homocitrulline-containing peptides related to type I and II collagen telopeptides. Arthritis Res Ther. 2015; 17: 2.

25. Turesson C, Mathsson L, Jacobbssom LTH, et al. Antibodies to modified citrullinated vimentin are associated with severe extra-articular manifestations in rheumatoid arthritis. Ann Rheum Dis. 2013; 72: 2047-8.

26. Gonzalez-Lopez L, Rocha-Muñoz AD, PonceGuarneros M, et al. Anti-cyclic citrullinated peptide (anti-CCp) and anti-mutated citrullinated vimentin (anti-MCV) relation with extra-articular manifestations in rheumatoid arthritis. J Immunol Res. 2014; 536050.

27. Lindenberg L, Spengler L, Bang H, et al. Restrictive IgG antibody response against mutated citrullinated vimentin predicts response to rituximab in patients with rheumatoid arthritis. Arthritis Res Ther. 2015; 17: 206.

28. Simon M, Girbal E, Sebbag M, et al. The cytokeratin filament-aggregating protein filaggrin is the target of the so-called "antikeratin antibodies," autoantibodies specific for rheumatoid arthritis. J Clin Invest. 1993; 92: 1387-93.

29. Wang X, Chen P, Cui J, et al. Keratin 8 is a novel autoantigen of rheumatoid arthritis. Biochem Biophys Res Commun. 2015; 465: 665-9.

30. Masson-Bessiere C, Sebbag M, Girbal-Neuhauser E, et al. The major synovial targets of the rheumatoid arthritis-specific antifilaggrin autoantibodies are deiminated forms of the $\alpha$ and $\beta$-Chains of fibrin. J Immunol. 2001; 166: 4177-84.

31. Nogueira N, Sebbag M, Chapuy-Regaud S, et al. Autoantibodies to deiminated fibrinogen are the most efficient serological criterion for the diagnosis of rheumatoid arthritis. Arthritis Res. 2002; 5: 1-35.

32. Cornillet M, Sebbag M, Verrouil E, et al. The fibrin-derived citrullinated peptide $\beta 60$ $74 \mathrm{Cit}_{60,72,74}$ bears the major ACPA epitope recognised by the rheumatoid arthritis-specific anticitrullinated fibrinogen autoantibodies and anti-CCP2 antibodies. Ann Rheum Dis. 2014; 73: $1246-52$.

33. Nogueira L, Cornillet M, Singwe-Ngandeu $\mathrm{M}$, et al. In Black Africans with rheumatoid arthritis, ACPA recognize citrullinated fibrinogen and the derived peptides $\alpha 36-50 \mathrm{Cit}_{38,42}$ and $\beta 60-74 \mathrm{Cit}_{60,72,74}$, like in Caucasians. Clin Immunol. 2014; 152: 58-64.

34. Billings PB, Hoch SO, White PJ, et al. Antibodies to the Epstein-Barr virus nuclear antigen and to rheumatoid arthritis nuclear antigen identify the same polypeptide. Proc Natl Acad Sci U S A. 1983; 80: 7104-8.

35. Cornillet M, Verrouil E, Cantagrel A, et al. In ACPA-positive RA patients, antibodies to EBNA35-58Cit, a citrullinated peptide from the Epstein-Barr nuclear antigen-1, strongly cross-react with the peptide $\beta 60-74 \mathrm{Cit}_{60,72,74}$ which bears the immunodominant epitope of citrullinated fibrin. Immunol Res. 2015; 61: 117-25.

36. Ronnelid J, Lysholm J, Engstrom-Laurent A, et al. Local anti-type II collagen antibody production in rheumatoid arthritis synovial fluid. Evidence for an HLA-DR4-restricted IgG response. Arthritis Rheum. 1994; 37: 1023-29.

37. Koivula M, Heliövaara M, Rissanen H, et al. Antibodies binding to citrullinated telopeptides of type I and type II collagens and to mutated citrullinated vimentin synergistically predict the development of seropositive rheumatoid arthritis. Ann Rheum Dis. 2012; 71: 1666-70.

38. Lundberg K, Kinloch A, Fisher BA, et al. Antibodies to citrullinated $\alpha$-enolase peptide 1 are specific for rheumatoid arthritis and crossreact with bacterial enolase. Arthritis Rheum. 2008; 58: 3009-19.

39. Umeda N, Matsumoto I, Ito I, et al. Anticitrullinated glucose-6-phosphate isomerase peptide antibodies in patients with rheumatoid arthritis are associated with HLA-DRB1 shared epitope alleles and disease activity. Clin Exp Immunol. 2012; 172: 44-53.

40. Mahdi H, Fisher BA, Källberg H, et al. Specific interaction between genotype, smoking and autoimmunity to citrullinated alpha-enolase in the etiology of rheumatoid arthritis. Nat Genet. 2009; 41: 1319-24.

41. Montes A, Dieguez-Gonzalez R, Perez-Pampin E, et al. Particular association of clinical and genetic features with autoimmunity to citrullinated $\alpha$-enolase in rheumatoid arthritis. Arthritis Rheum. 2011; 63: 654-61. 
42. Lee JY, Choi IA, Kim J, et al. Association between anti- Porphyromonas gingivalis or anti- $\alpha$-enolase antibody and severity of periodontitis or rheumatoid arthritis (RA) disease activity in RA. BMC Musculoskelet Disord. 2015; 16: 190.

43. Fisher BA, Plant D, Brode M, et al. Antibodies to citrullinated $\alpha$-enolase peptide 1 and clinical and radiological outcomes in rheumatoid arthritis. Ann Rheum Dis. 2011; 70: 1095-8.

44. Matsumoto I, Staub A, Benoist C, Mathis D. Arthritis provoked by linked T and B cell recognition of a glycolytic enzyme. Science. 1999; 286: 1732-35.

45. van Beers JJBC, Schwarte CM, Stammen-Vogelzangs $\mathrm{J}$, et al. The rheumatoid arthritis synovial fluid citrullinome reveals novel citrullinated epitopes in apolipoprotein E, myeloid nuclear differentiation antigen, and $\beta$-actin. Arthritis Rheum. 2013; 65: 69-80.

46. Foulquier C, Sebbag M, Clavel C, et al. Peptidyl arginine deiminase type 2 (PAD-2) and PAD-4 but not PAD-1, PAD-3, and PAD-6 are expressed in rheumatoid arthritis synovium in close association with tissue inflammation. Arthritis Rheum. 2007; 56: 3541-53.

47. Halvorsen EH, Pollmann S, Gilboe I-M, et al. Serum IgG antibodies to peptidylarginine deiminase 4 in rheumatoid arthritis and associations with disease severity. Ann Rheum Dis. 2008; 67: 414-17.

48. Ishigami A, Uchida Y, Miyazaki T, et al. Two novel sandwich ELISAs identify PAD4 levels and PAD4 autoantibodies in patients with rheumatoid arthritis. Mod Rheumatol. 2013; 23: 794-803.

49. Ferucci ED, Darrah E, Smolik I, et al. Prevalence of anti-peptidylarginine deiminase type 4 antibodies in rheumatoid arthritis and unaffected first-degree relatives in indigenous north american populations. J Rheumatol. 2013; 40: 1523-28.

50. Giles JT, Darrah E, Danoff S, et al. Association of cross-reactive antibodies targeting peptidylarginine deiminase 3 and 4 with rheumatoid arthritis-associated interstitial lung disease. PLoS One. 2014; 9: e98794.

51. Umeda N, Matsumoto I, Kawaguchi H, et al. Prevalence of soluble peptidylarginine deiminase 4 (PAD4) and anti-PAD4 antibodies in autoimmune diseases. Clin Rheumatol. 2016; 35: 1181-8.

52. Darrah E, Giles JT, Ols ML, et al. Erosive rheumatoid arthritis is associated with antibodies that activate PAD4 by increasing calcium sensitivity. Sci Trasl Med. 2013; 186: $186 r a 65$.

53. Wang Z, Nicholls SJ, Rodriguez ER, et al. Protein carbamylation links inflammation, smoking, uremia and atherogenesis. Nat Med. 2007; 13: 1176-84.
54. Shi J, van Veelen PA, Mahler M, et al. Carbamylation and antibodies against carbamylated proteins in autoimmunity and other pathologies. Autoimmun Rev. 2014; 13: 225-30.

55. Brink M, Verheul MK, Rönnelid J, et al. Anticarbamylated protein antibodies in the presymptomatic phase of rheumatoid arthritis, their relationship with multiple anti-citrulline peptide antibodies and association with radiological damage. Arthritis Res Ther. 2015; 17 : 25.

56. Gan RW, Leender A, Trouw LA, et al. Anticarbamylated protein antibodies are present prior to rheumatoid arthritis and are associated with its future diagnosis anti-carbamylated protein antibodies are present prior to rheumatoid arthritis and are associated with its future diagnosis. J Rheumatol. 2015; 42: 572-9.

57. Shi J, van Steenbergen HW, van Nies JAB, et al. The specificity of anti-carbamylated protein antibodies for rheumatoid arthritis in a setting of early arthritis. Arthritis Res Ther. 2015; 17: 339.

58. Shi J, van de Stadt LA, Levarht EWN, et al. Anti-carbamylated protein antibodies are present in arthralgia patients and predict the development of rheumatoid arthritis. Arthritis Rheum. 2013; 65: 911-15.

59. Pecani A, Alessandri C, Spinelli FR, et al. Prevalence, sensitivity and specificity of antibodies against carbamylated proteins in a monocentric cohort of patients with rheumatoid arthritis and other autoimmune rheumatic disease. Arthritis Res Ther. 2016; 18: 276.

60. Humphreys JH, Verheul MK, Barton A, et al. Anticarbamylated protein antibodies are associated with long-term disability and increased disease activity in patients with early inflammatory arthritis: results from the Norfolk Arthritis Register. Ann Rheum Dis. 2016; 75 : 1139-44.

61. Jiang X, Trouw LA, Wesemael TJ Van, et al. Anti-CarP antibodies in two large cohorts of patients with rheumatoid arthritis and their relationship to genetic risk factors, cigarette smoking and other autoantibodies. Ann Rheum Dis. 2014; 73: 1761-8.

62. Yee A, Webb T, Seaman A, et al. Anti-CarP antibodies as promising marker to measure joint damage and disease activity in patients with rheumatoid arthritis. Immunol Res. 2014; 61: 24-30.

63. Shi J, van de Stadt LA, Levarht EWN, et al. Anti-carbamylated protein (anti-CarP) antibodies precede the onset of rheumatoid arthritis. Ann Rheum Dis. 2014; 73: 780-3.

64. Strollo R, Ponchel F, Malmstro V, et al. Autoantibodies to post-translationally modified type II collagen as potential biomarkers for rheumatoid arthritis. Arthritis Rheum. 2013; 65: 1702-12. 
65. Nawakowska-Plaza A, Potaczek DP, Gluszko P, Undas A. Antibodies to N-homocysteinylated albumin and haemoglobin in patients with rheumatoid arthritis: a potential new marker of disease severity. Scand J Rheumatol. 2014; 43: $17-21$.

66. Maksymowych WP, Boire G, van Schaardenburg D, et al. 14-3-3 $\eta$ autoantibodies: diagnostic use in early rheumatoid arthritis. J Rheumatol. 2015; 42: 1587-94.

67. Maslyanskiy A, Lazareva N, Olinek P, et al. Anti-hnRNP B1 (RA33) autoantibodies are associated with the clinical phenotype in russian patients with rheumatoid arthritis and systemic sclerosis. J Immunol Res. 2014; 516593.

68. Al-mughales JA. Immunodiagnostic significance of anti-RA33 autoantibodies in Saudi patients with rheumatoid arthritis. J Immunol Res. 2015; 604305.

69. Shoda H, Hanata N, Sumitomo S, et al. Immune responses to mycobacterial heat shock protein 70 accompany self-reactivity to human BiP in rheumatoid arthritis. Nat Publ Gr. 2016; 6: $1-10$.

70. Dai H, Dong H, Gong F, et al. Disease association and arthritogenic potential of circulating antibodies against the $\alpha 1,4$-polygalacturonic acid moiety. J Immunol. 2014; 192: 4533-40.

71. Hauser B, Riches PL, Gilchrist T, et al. Autoantibodies to osteoprotegerin are associated with increased bone resorption in rheumatoid arthritis. Ann Rheum Dis. 2015; 74: 1631-2.

72. Alunno A, Caneparo V, Bistoni O, et al. Circulating interferon-inducible protein IFI16 correlates with clinical and serological features in rheumatoid arthritis. Arthritis Care Res. 2016; 68: 440-5.

73. Lopatnikova JA, Golikova EA, Shkaruba NS, et al. Analysis of the levels of tumour necrosis factor (TNF), autoantibodies to TNF, and soluble TNF receptors in patients with rheumatoid arthritis. Scand J Rheumatol. 2013; 42: 429-32.

74. Thiele GM, Duryee MJ, Anderson DR, et al. Malondialdehyde-acetaldehyde adducts and anti-malondialdehyde-acetaldehyde antibodies in rheumatoid arthritis. Arthritis Rheumatol. 2015; 67: 645-55.

75. Sharma S, Ghosh S, Singh LK, et al. Identification of autoantibodies against transthyretin for the screening and diagnosis of rheumatoid arthritis. PLoS One. 2014; 9: e93905.

76. Guo Y, Wu Q, Ni B, et al. Tryptase is a candidate autoantigen in rheumatoid arthritis. Immunology 2014; 142: 67-77.

77. Liu C, Wei Y, Wang J, et al. Carbonic anhydrases III and IV autoantibodies in rheumatoid arthritis, systemic lupus erythematosus, diabetes, hypertensive renal disease, and heart failure. Clin Dev Immunol. 2012; 354594.

78. Bouillet L, Mannic T, Treillard B, et al. Autoantibodies to vascular endothelial cadherin in humans: association with autoimmune diseases. Lab Investig. 2013; 93: 1194-202.

79. Biswas S, Sharma S, Saroha A, et al. Identification of novel autoantigen in the synovial fluid of rheumatoid arthritis patients using an immunoproteomics approach. PLoS One. 2013; 8: e56246.

80. Charpin C, Arnoux F, Martin M, et al. New autoantibodies in early rheumatoid arthritis. Arthritis Res Ther. 2013; 15: R78. 